\title{
Assessment of the Ameliorative Effect of Vitamin C on Manganese Induced Liver Damage in Female Albino Rats
}

\author{
Akpan Udo Ekanem ${ }^{1}$, Kudighe Patrick Udoh ${ }^{2 *}$, Ekemini Imoh Johnson ${ }^{1}$ and Kingsley Lucky Akpan ${ }^{1}$ \\ ${ }^{1}$ Department of Anatomy, University of Uyo, Nigeria \\ ${ }^{2}$ Community Health Officers' Training School, University of Uyo Teaching Hospital, Nigeria \\ *Corresponding Author: Kudighe Patrick Udoh, Community Health Officers' Training School, University of Uyo Teaching Hospital, \\ Nigeria.
}

Received: October 03, 2019; Published: October 30, 2019

DOI: $10.31080 /$ ASMS.2019.03.0458

\begin{abstract}
Manganese is one of the minerals required in trace amounts for normal functioning of the body. When present in high concentration, manganese gradually leads to morphological changes that interfere with many biological processes through oxidative stress mechanism. This study was carried out to investigate the hepatoprotective effect of vitamin $\mathrm{C}$ on manganese chloride induced toxicity of the rat liver. Thirty female Wistar rats weighing between 133 - 268g were used for the experiment. The animals were randomly divided into six groups of five animals each numbered 1 - 6 . Group 1 served as control and received feed and water ad libitum. Group 2 received vitamin C $100 \mathrm{mg} / \mathrm{kg}$ body weight of rats. Groups 3 and 4 received manganese dichloride salt $148.4 \mathrm{mg} / \mathrm{kg}$ and $445.2 \mathrm{mg} /$ $\mathrm{kg}$ body weight of rat, respectively. Groups 5 and 6 received manganese dichloride $148.4 \mathrm{mg} / \mathrm{kg}$ and $445.2 \mathrm{mg} / \mathrm{kg}$ body weight of rat along with $100 \mathrm{mg} / \mathrm{kg}$ body weight of vitamin C, respectively. Administration was done orally for 18 days. After the $18^{\text {th }}$ day, animals were sacrificed by chloroform inhalation; the liver was harvested, processed and stained with haematoxylin and eosin. Microscopic observation showed dilated sinusoids, degeneration of portal tract, erosion of lining of central vein and sinusoids, hypertrophied and vacuolated hepatocytes, and congested central vein in the manganese dichloride treated groups. The groups treated with manganese dichloride along with vitamin $\mathrm{C}$ showed some level of ameliorative effect although dilated sinusoids and vacuolated hepatocytes persisted. Statistically the weight of the animals showed significant increase in group 3 and decrease in groups 4, 5 and 6 compared to control. Hepato-somatic indices showed no significant difference compared to control. In conclusion, exposure to manganese dichloride showed some histopathological effects on the liver of female albino Wistar rats when consumed excessively and vitamin $\mathrm{C}$ ameliorated the effect of this salt on the liver.
\end{abstract}

Keywords: Liver; Manganese Dichloride; Vitamin C; Histology; Rat

\section{Introduction}

Manganese is one of the trace elements in the body required for various physiological and biochemical processes. The major source of manganese in the body is through the consumption of grains, vegetables and seafood. It is also provided as supplement especially in many multivitamin drugs [1,2]. After ingestion, manganese is rapidly absorbed through the digestive tract into the circulation and distributed to other parts of the body. The foremost regulation of the bioavailability of manganese is by its absorption through the intestinal tract, which is dependent on the availability of other cations, such as iron and calcium, to compete for the divalent metal transporter 1 (DMT1) [3-5]. However, in manganese-rich environments, manganese can also enter the body through inhalation and dermal permeation. Within the body, the liver contains the high- 
est concentration of manganese and it is also responsible for the excretion of manganese through bile [4,6,7]. Thus, the liver plays an important role in the storage, distribution and elimination of manganese.

Despite its role in the body's mechanisms, excessive accumulation of manganese can lead to severe toxicity in vital organs of the body. According to Williams and McClure [8], acute lethality of manganese in animals varies depending on the chemical species and route of exposure. Studies with rats show that gavage administration, of manganese chloride, is the most lethal route of exposure [6,8]. However, exposure limits and toxicity levels are not well known for humans. Neonates and infants are at higher risk of excessive accumulation of manganese due to underdevelopment of the biliary system, but the toxic effects are more expressed in the elderly [9]. The tolerable daily intake for manganese is set at $0.06 \mathrm{mg} / \mathrm{kg}$, with upper range intake value of $11 \mathrm{mg} /$ day for an adult of $60 \mathrm{~kg}$ body weight. The adequate intake value is $2.3 \mathrm{mg} /$ day, $1.8 \mathrm{mg} /$ day, and $2 \mathrm{mg} /$ day for adult male, adult female and pregnant or lactating women, respectively $[7,9]$.

Although the brain is the primary target of manganese toxicity, many patients have been diagnosed with liver impairments involving micronodular cirrhosis, unconjugated hyperbilirubinemia and elevated transaminase. Hepatotoxicity of manganese have also been shown through several animal experimentation studies [10-12]. Considering the vital role of the liver in manganese metabolism, destruction of the liver exposes other organs to the destructive effects of excess manganese. Since the accumulation of manganese within the body is silent over time [1], there is need for substances that can counter the effects of excess accumulation. Therefore, this study was carried out to investigate the hepatoprotective effect of vitamin $\mathrm{C}$ against excess manganese accumulation in the body.

\section{Materials and Methods}

The experiment was carried out in the animal facility of Basic Medical Sciences, University of Uyo, Nigeria. Histological preparations were done at the histology laboratory of the Department of Anatomy, University of Uyo Nigeria. Ethical approval was duly obtained from the Ethical Committee of Faculty of Basic Medical Sciences, University of Uyo, Nigeria.
A total of 30 female albino rats weighing between 133 to $268 \mathrm{~g}$ were used for the study. Five animals were housed in a cage to allow considerable degree of freedom with rubber cylinders to enhance their environment. The rats were given food and water ad libitum. All animal experiments were performed in accordance with the National Institute of Health Guide for the use and care of laboratory animals [13].

The rats were divided at random into six groups of five each. Group 1 was control and 2 to 6 were treatment groups as illustrated in table 1. Manganese dichloride tetrahydrate salt was utilized at $\mathrm{LD}_{50}$ of $1484 \mathrm{mg} / \mathrm{kg}$ body weight (Holbrook., et al. 1975). $10 \%$ and $30 \%$ of $\mathrm{LD}_{50}$ represented low and high dose that was administered respectively. The weight of the animals were taken and recorded every six days.

\begin{tabular}{|l|l|l|l|}
\hline 1 & Control & $\begin{array}{l}\text { Water and Feed } \\
\text { alone }\end{array}$ & 18 Days \\
\hline 2 & Vitamin C & $\begin{array}{l}\text { Vitamin C 100 mg/kg } \\
\text { body weight }\end{array}$ & 18 Days \\
\hline 3 & $\begin{array}{l}\text { Manganese dichloride } \\
\text { (Low dose) }\end{array}$ & $\begin{array}{l}\text { Manganese dichloride } \\
148.4 \mathrm{mg} / \mathrm{kg} \text { body } \\
\text { weight }\end{array}$ & 18 Days \\
\hline 4 & $\begin{array}{l}\text { Manganese dichloride } \\
\text { (High dose) }\end{array}$ & $\begin{array}{l}\text { Manganese dichloride } \\
445.2 \mathrm{mg} / \mathrm{kg} \text { body } \\
\text { weight }\end{array}$ & 18 Days \\
\hline 5 & $\begin{array}{l}\text { Manganese dichloride } \\
\text { (Low dose) and } \\
\text { Vitamin C }\end{array}$ & $\begin{array}{l}\text { Manganese dichloride } \\
148.4 \mathrm{mg} / \mathrm{kg} \text { body } \\
\text { weight + Ascorbic acid } \\
100 \mathrm{mg} / \mathrm{kg}\end{array}$ & 18 Days \\
\hline 6 & $\begin{array}{l}\text { Manganese dichloride } \\
\text { (High dose) and } \\
\text { Vitamin C }\end{array}$ & $\begin{array}{l}\text { Manganese dichloride } \\
445.2 \mathrm{mg} / \mathrm{kg} \text { body } \\
\text { weight + Ascorbic } \\
\text { acid100 mg/kg }\end{array}$ & 18 Days \\
\hline
\end{tabular}

Table 1: Experimental Design.

\section{Drug administration}

Manganese dichloride tetrahydrate $\left(\mathrm{MnCl}_{2} \cdot 4 \mathrm{H}_{2} \mathrm{O}\right)$ was used for the study. White tablets of vitamin $\mathrm{C}$ produced by Emzor Nigeria Ltd. was crushed into powdered form and used for the study. Each dose was diluted in $1 \mathrm{ml}$ of water and given by oral gavage. Manganese dichloride was co-administered daily according to treatment groups for 18 days. 


\section{Sample collection}

After 18 days administration, the animals were weighed and euthanized by chloroform inhalation. Each liver was excised and weighed. After weighing, the liver was rinsed in normal saline to clear all blood stains before fixing in $10 \%$ buffered formalin for tissue processing.

\section{Organo-somatic index}

The organo-somatic index was calculated using the formula [14].

\section{Weight of Organ $\times 100$}

Weight of animal 1

Tissue processing

After fixation, the liver was cut transversely to remove 5 - $6 \mathrm{~mm}$ of tissue from the inferior pole for histological processing. The cut sections were put through series of tissue processing procedures for hematoxylin and eosin ( $\mathrm{H}$ and $\mathrm{E}$ ) staining as described in Bancroft and colleagues, (2013).

\section{Statistical analysis}

All data were expressed as Mean \pm Standard Error of Mean (SEM). Evaluation of the significant difference between means of different experimental groups and control group was performed by one way analysis of variance (ANOVA) at confidence limits of
95\%. Least significant differences (LSD) were used to determine significant results. Differences between groups were considered statistically not significant at $\mathrm{p}>0.05$.

\section{Results}

\section{Body weight}

The body weight of groups 1,3 , and 4 showed a trend towards weight gain in the animals, while groups 5 and 6 showed trend towards weight loss in the animals compared to control (Table 2 and Figure 1).

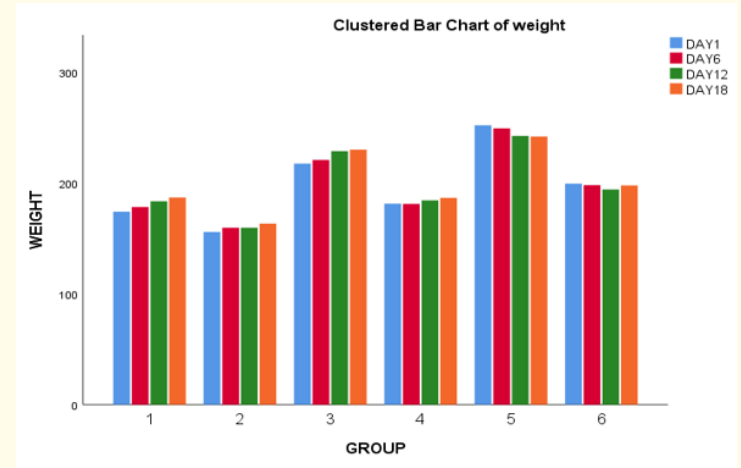

Figure 1: Effect of manganese dichloride and vitamin $\mathrm{C}$ on body weight of Wistar rats.

\begin{tabular}{|l|c|c|c|c|c|c|}
\hline \multicolumn{2}{|l|}{ Control (g) } & \multicolumn{2}{l|}{ Treated groups (g) } \\
\hline Duration & Group 1 (n=5) & Group 2 (n=5) & Group 3 (n=5) & Group 4 (n=5) & Group 5 (n=5) & Group 6 (n=5) \\
\hline Day 1 & $174.0 \pm 11.29$ & $155.8 \pm 12.29$ & $217.3 \pm 7.10^{*}$ & $181.2 \pm 4.72$ & $252.0 \pm 16.64^{*}$ & $198.25 \pm 34.87^{*}$ \\
\hline Day 6 & $178.2 \pm 9.98$ & $159.5 \pm 10.47$ & $220.7 \pm 6.02^{*}$ & $181.0 \pm 4.83$ & $249.2 \pm 14.89^{*}$ & $197.25 \pm 4.03$ \\
\hline Day 12 & $183.4 \pm 10.92$ & $159.5 \pm 13.23^{*}$ & $228.7 \pm 2.18^{*}$ & $184.3 \pm 5.90$ & $242.4 \pm 13.97^{*}$ & $194.75 \pm 4.79$ \\
\hline Day 18 & $186.8 \pm 12.15$ & $163.3 \pm 13.30^{*}$ & $230.0 \pm 5.57^{*}$ & $186.5 \pm 5.80$ & $241.8 \pm 12.07^{*}$ & $197.67 \pm 2.89$ \\
\hline
\end{tabular}

Table 2: Effect of manganese dichloride and vitamin C on body weight of Wistar rats.

*values significantly different from corresponding control $(p<0.05)$ (mean \pm SD).

\section{Organo-somatic indices}

Hepato-somatic indices were not statistically different $(\mathrm{p}>$ 0.05). While other groups have an insignificant decrease as compared to group A, there was an insignificant increase in group B
(Table 3). While the mean brain-weight result showed no significant difference in any group, the organo-somatic index for the brain indicated significant increase in group B and a significant decrease in group $\mathrm{E}$. 


\begin{tabular}{|c|c|}
\hline Groups & Organo-somatic Indices \\
\hline 1 & $3.82 \pm 0.13$ \\
\hline 2 & $4.14 \pm 0.22$ \\
\hline 3 & $3.54 \pm 0.15$ \\
\hline 4 & $3.61 \pm 0.74$ \\
\hline 5 & $3.40 \pm 0.12$ \\
\hline 6 & $3.72 \pm 0.07$ \\
\hline
\end{tabular}

Table 3: Effect of manganese dichloride and vitamin $C$ on Organo-somatic indices of Wistar rats Mean \pm SEM. $P>0.05$.

\section{Histological observations}

The photomicrographs of groups 1 and 2 showed normal histoarchitecture. The radiation of the hepatocytes from the central vein interspersed by sinusoids were clearly illustrated, and there was no sign of toxicity within the tissue. Photomicrographs of groups 3 and 4 animals showed marked alterations in normal liver histoarchitecture. Hepatocytes were hypertrophied and possess fatty changes. Sinusoids and central veins were congested and dilated. There was also degeneration in portal tract. These alterations are mild in group 3 as compared to group 4 (Figure 2). Groups 5 and 6 showed normal histoarchitecture. There were marked reduction of hypertrophied hepatocytes and fatty changes seen in the cells compared to groups 3 and 4 . Dilation of sinusoids and central vein were also reduced (Figure 2).

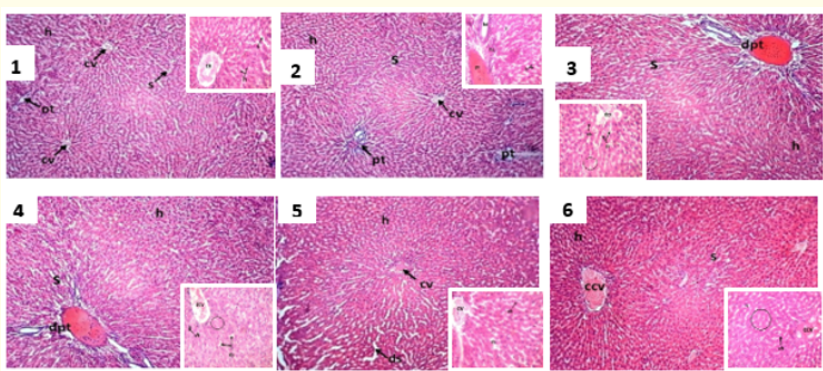

Figure 2: Photomicrographs of liver of the experimental rats. 1: liver from control group showing normal cellular architecture. 2: liver from vitamin $\mathrm{C}$ treatment group showing normal liver architecture. 3: liver from group treated with low dose $\mathrm{MnCl} 2$ showing alterations in liver morphology. 4: liver from high dose $\mathrm{MnCl} 2$ treatment group showing alterations in liver morphology.

5: liver from low dose $\mathrm{MnCl} 2$ and vitamin $\mathrm{C}$ treatment group showing alteration in liver morphology. 6: liver from high dose $\mathrm{MnCl} 2$ and vitamin $\mathrm{C}$ treatment group showing alterations in liver morphology. cv-central vein, s-sinusoidal Space, h-hepatocytes, pt- portal tract, pv-portal vein, ha-hepatic artery, bd- bile duct, ccv-congested central vein, cs-congested sinusoidal space, vh-vacuolated hepatocytes, ds-dilated sinusoids, dpt-degerative portal tract, dcv-dilated central vein (H\&E; x100; insert x400).

\section{Discussion}

The liver is the heaviest organ in the body and functions as a gland, storage, sensory and excretory organ. It is responsible for most of the metabolic activities in the body including carbohydrate, lipid, and protein metabolism as well as processing of drugs and hormones. It screens and detoxifies substances within the blood. It is strategically placed within the abdomen to directly receive and detoxify blood drained from the intestinal tract before the blood reaches the heart for general circulation. The liver is the primary storage site for glycogen, vitamins, and minerals. It is also responsible for the synthesis of plasma proteins, bile salts and activation of vitamin D. In addition to excretion of metabolic waste, the liver monitors the concentration of substances within the blood and excretes excess substances such as manganese through bile. It is one of the organs in adult human with the capacity to regenerate from injury. However, chronic injury to the liver can interfere with its regenerative capacity leading to fibrosis and impairment in its numerous functions $[15,16]$. The liver also becomes weak and injured when it is overloaded with work such as excess accumulation of substances within the blood as was demonstrated in this study. According to Cabot [16], overlapping of detoxification pathways leads to build up of toxins leading to higher levels of free radicals, excess of which may damage the liver.

It has been reported that one of the mechanisms excess accumulation of manganese induces toxicity is through oxidative stress [4,17-19]. This necessitated the investigation of the possible counter-effect of an antioxidant such as vitamin $\mathrm{C}$, which is one of the most powerful antioxidants in the body. Vitamin C is commonly available in many vegetables, fruits and as dietary supplements. It is an essential vitamin required as cofactor in many enzymatic processes including collagen synthesis. Its anti-oxidative activity and ameliorative potential have been explored and confirmed in many studies. Its hepatoprotective effects against liver damage by heavy metals and chemicals have been well investigated with positive results [20-23]. In this study, however, insignificant ameliorative activity was observed for vitamin $\mathrm{C}$ against hepatotoxic effect of manganese dichloride.

There was an insignificant decrease in hepato-somatic indices of treatment groups compared to control. This result contradicts similar researches by Zhang., et al. [10], Haung., et al. [11], and Chandel and Jain [12], who observed an increase in liver weight. Rats that received vitamin $\mathrm{C}$ alone showed a little increase as compared to control. In similar studies by Chandel and Jain [12], rats exposed to manganese dichloride showed a trend towards weight gain. Statistical analysis showed significant loss in body weight for group 4 rats, treated with high dose of manganese dichloride $\left(\mathrm{MnCl}_{2}\right)$ compared to control, while there was negligible gain in body weight for 
group 3 rats treated with low dose of $\mathrm{MnCl}_{2}$ compared to control. This might be associated with the dose dependent effect of manganese chloride on appetite. While manganese indirectly maintains proper appetite through the production of thyroxine hormone, at high concentrations, it impairs with appetite and decreases food consumption [8,9,24-26]. Group 5 treated with co-administration of vitamin $\mathrm{C}$ and low dose of $\mathrm{MnCl}_{2}$ showed comparable decrease in body weight with group 3 . This may be due to direct or indirect normalization effect of vitamin $\mathrm{C}$, on the hyper-activity of thyroxine from increased availability of manganese. On the contrary, no difference was observed for weight changes between group 4 and group 6, with co-administration of vitamin and $\mathrm{MnCl}_{2}$, which may result from overshadowing effect of excess manganese.

Histological observations showed normal liver histo-architecture in group 1 (control) and group 2 (administered with only vitamin $\mathrm{C}$ ). There were alterations in $\mathrm{MnCl}_{2}$ treated rats with specific injury to central vein, portal triad and hepatocytes. The hepatocytes hypertrophied and degeneration was observed in some areas. This morphological changes have conventionally been attributed to alterations in the injured cells because of hydropic change and microsomal enzyme induction secondary to exposure to xenobiotics [15]. Degenerative changes in portal tract, diffused sinusoids, degeneration of lining of the central vein, dilation and congestion of central vein and sinusoids were also observed on micrographs of treatment groups. This result agrees with those of Lebda., et al. [27], Huang., et al. [11] and Chandel and Jain [12]. Congestion and dilation have been reported to occur when the venous outflow is blocked as a result of obstruction of arterial outflow either by clotting or disruption of veins [28,29]. This suggests an extended effect of manganese on the circulatory system. Similar to findings by Huang., et al. [30], it was also found that the severity of these alterations is dose dependent as changes in rats administered with high dose of $\mathrm{MnCl}_{2}$ were more severe compared to those with low dose. Although co-administration with vitamin $\mathrm{C}$ did not completely ameliorate the histoarchitectural alterations from excess $\mathrm{MnCl}_{2}$, the severity was drastically reduced. This suggests two possibilities: either the anti-oxidative property of vitamin $C$ is not strong enough to counter the oxidative stress induced by excess accumulation of manganese; or excess accumulation of manganese induces its toxic effects through other mechanisms in addition to oxidative stress.

\section{Conclusions}

This study showed that although the toxic effect of excess exposure to manganese dichloride $\left(\mathrm{MnCl}_{2}\right)$ may not be expressed in body weight changes and macroscopic observations, the cytotoxic effect is progressively severe and rapid. Vitamin C may slow down its progress, but does not completely protect against it, suggesting the involvement of other mechanisms to the toxicity in addition to oxidative stress. It is recommended that more investigations be carried out into the mechanisms of toxicity of excess accumulation of manganese in the body so that appropriate protective measures can be developed, especially for the liver.

\section{Bibliography}

1. Howe PD., et al. "Manganese and its compounds: Environmental aspects". In Concise International Chemical Assessment. Geneva: World Health Organization (2004).

2. Santamaria AB and Sulsky SI. "Risk Assessment of an Essential Element: Manganese". Journal of Toxicology and Environmental Health Part A: Current Issues 73 (2010): 128-155.

3. Ye Q., et al. "Influence of iron metabolism on manganese transport and toxicity". Metabolomics 9.9 (2017): 1028-1046.

4. Chen P., et al. "Manganese metabolism in humans". Frontiers in Bioscience 23 (2018): 1655-1679.

5. Wessling-Resnick M. Manganese Metabolism and Toxicity (2019).

6. USEPA. Health Effects Support Document for Manganese (2003): 6,1-7,52.

7. USEPA. Drinking Water Health Advisory for Manganese (2004): 9-29.

8. Williams M and McClure PR. "Health Effects. In Toxicological Profile for Manganese Georgia, USA: U.S”. Department of Health and Human Services (2012): 39-360.

9. WHO. "Manganese in Drinking-water". In WHO Guidelines for Drinking-water Quality World Health Organization 1.140 (2011).

10. Zhang S., et al. "Effect of manganese chloride exposure on liver and brain mitochondria function in rats". Environmental Research 93 (2003): 149-157. 
11. Huang P., et al. "Manganese effects in the liver following subacute or subchronic manganese chloride exposure in rats". Ecotoxicology and Environmental Safety 74 (2011b): 615-622.

12. Chandel M and Jain GC. "Manganese Chloride Induced Hepatic and Renal Toxicity in Wistar Rats". Toxicology International 23.3 (2016): 212-220.

13. National Research Council. "Guide for the Care and Use of Laboratory Animals, 8th edition". National Academies Press (2011).

14. Ebong PE., et al. "The Antidiabetic Efficacy of Combined Extracts from Two Continental Plants: Azadirachtaindica. (A.juss) (Neem) and Vernoniaamygdalina (del.) African Bitter Leaf". American Journal of Biotechnology 4.3 (2008): 239-244.

15. Cattley RC and Popp JA. "Liver". In W. M. Haschek, C. G. Rousseaux, and M. A. Wallig (Eds.), Handbook of Toxicologic Pathology San Diego: Academic Press 2 (2002): 187-222.

16. Cabot S. "The liver detoxification". In The Liver Cleansing Diet (2014).

17. Kontur PJ and Fechter LD. "Brain regional manganese levels and monoamine metabolism in manganese-treated neonatal rats". Neurotoxicology and Teratology 10 (1988): 295-303.

18. Avila DS., et al. "Manganese in health and disease". Metal Ions in Life Sciences 13 (2013): 199-227.

19. Peres TV., et al. "And quot; Manganese-induced neurotoxicity: a review of its behavioral consequences and neuroprotective strategies and quot". BMC Pharmacology and Toxicology 17.1 (2016): 57.

20. Banerjee PS., et al. "Vitamin C Combats Arsenic-Induced Oxidative Stress in Mice Liver". Ecotoxicology and Environmental Safety 7.2 (2008): 639-649.

21. Rajamanickam V and Muthuswamy N. "Effect of Heavy Metals Induced Toxicity on Metabolic Biomarkers in Common Carp (Cyprinus carpio L.)". Maejo International Journal of Science and Technology 2.1 (2008): 192-200.

22. Awodele 0., et al. "Modulatory Activity of Antioxidant against the Toxicity of Rifampicin in Vivo". Instituto de Mediana Tropica de Sao 52.1 (2010): 43-46.
23. Al-shathly MR., et al. "The Preventive Effect of Vitamin C upon Added Methyl Tertiary Butyl Ether (MTBE) in Drinking Water on the Liver of Albino Mice". International Journal of Research in Chemistry and Environment 2.2 (2012): 214-228.

24. Keen CL and Zidenberg-Cherr S. "Manganese”. In B. Caballero, L. Trugo, and P. M. Finglas (Eds.), Encyclopedia of Food Sciences and Nutrition U.S.A.: Academic Press (2003): 3686-3691.

25. Goodson A. 10 evidence-based benefits of manganese (2018).

26. Patil K. 13 Amazing benefits of manganese (2019).

27. Lebda MA., et al. "Neurohepatic toxicity of subacute manganese chloride exposure and potential chemoprotective effects of lycopene". Neurological Toxicology 33 (2012): 98-100.

28. Degott $\mathrm{C}$ and Potet F. "Peliosis hepatitis and sinusoidal dilatation". Archive in Anatomy Cytology and Pathology 32 (1984): 296-300.

29. Denninger MH and Chait Y. "Cause of portal or hepatic venous thrombosis in adults: The role of multiple concurrent factors". Hepatology 31 (2000): 587-591.

30. Huang P., et al. "Ecotoxicology and Environmental Safety Manganese effects in the liver following subacute or subchronic manganese chloride exposure in rats". Ecotoxicology and Environmental Safety 74.4 (2011a): 615-622.

\section{Volume 3 Issue 11 November 2019}

(c) All rights are reserved by Kudighe Patrick Udoh., et al. 